University of Windsor

Scholarship at UWindsor

2-17-2016

\title{
Predictors of Academic Procrastination in Asian International College Students
}

\author{
Robert Jay Lowinger \\ Bluefield State College \\ B.C.H Kuo \\ University of Windsor \\ Hyun-A Song \\ University of Pittsburgh \\ Lakshmi Mahadevan \\ Texas A\&M Agrilife Extension \\ Eunyoung Kim \\ Seton Hall University \\ See next page for additional authors \\ Follow this and additional works at: https://scholar.uwindsor.ca/psychologypub \\ Part of the Psychology Commons

\section{Recommended Citation} \\ Lowinger, Robert Jay; Kuo, B.C.H; Song, Hyun-A; Mahadevan, Lakshmi; Kim, Eunyoung; Liao, Kelly Yu-Hsin; \\ Chang, Catherine Y.; Kwon, Kyong-Ah; and Han, Suejung. (2016). Predictors of Academic Procrastination \\ in Asian International College Students. Journal of Student Affairs Research and Practice, 53 (1), 90-104. \\ https://scholar.uwindsor.ca/psychologypub/49
}

This Article is brought to you for free and open access by the Department of Psychology at Scholarship at UWindsor. It has been accepted for inclusion in Psychology Publications by an authorized administrator of Scholarship at UWindsor. For more information, please contact scholarship@uwindsor.ca. 


\section{Authors}

Robert Jay Lowinger, B.C.H Kuo, Hyun-A Song, Lakshmi Mahadevan, Eunyoung Kim, Kelly Yu-Hsin Liao, Catherine Y. Chang, Kyong-Ah Kwon, and Suejung Han 


\section{Journal of Student Affairs Research and Practice}

\section{Predictors of Academic Procrastination in Asian International College Students}

Robert Jay Lowinger, Ben C.H. Kuo, Hyun-A Song, Lakshmi Mahadevan, Eunyoung Kim, Kelly Yu-Hsin Liao, Catherine Y. Chang, Kyong-Ah Kwon \& Suejung Han

To cite this article: Robert Jay Lowinger, Ben C.H. Kuo, Hyun-A Song, Lakshmi Mahadevan, Eunyoung Kim, Kelly Yu-Hsin Liao, Catherine Y. Chang, Kyong-Ah Kwon \& Suejung Han (2016) Predictors of Academic Procrastination in Asian International College Students, Journal of Student Affairs Research and Practice, 53:1, 90-104

To link to this article: http://dx.doi.org/10.1080/19496591.2016.1110036

Published online: 17 Feb 2016.

Submit your article to this journal ¿

ai

View related articles $\sqsubset$

View Crossmark data $₫$ 


\title{
Predictors of Academic Procrastination in Asian International College Students
}

\author{
Robert Jay Lowinger, Bluefield State College \\ Ben C.H. Kuo, University of Windsor \\ Hyun-A Song, University of Pittsburgh \\ Lakshmi Mahadevan, Texas A\&M AgriLife Extension \\ Eunyoung Kim, Seton Hall University \\ Kelly Yu-Hsin Liao, University of Houston \\ Catherine Y. Chang, Georgia State University \\ Kyong-Ah Kwon, Georgia State University \\ Suejung Han, Illinois State University
}

\begin{abstract}
This study examined the relationships among acculturative stress, coping styles, self-efficacy, English language proficiency, and various demographic characteristics as predictors of procrastination behavior in Asian International students ( $N=255)$ studying in the United States. Results of multiple logistic regression indicated that a collective coping style, avoidant coping style, academic self-efficacy, and English language proficiency were the significant predictors of academic procrastination in non-Indian Asian international students. Implications for college student affairs professionals and researchers are addressed.
\end{abstract}

Academic procrastination is defined as an irrational delay in performing academic tasks required of students (e.g., studying for exams, reading assignments, performing academic administrative and attendance tasks) (Özer, Demir, \& Ferrari, 2009). Academic procrastination is a significant problem for college students, a moderate to strong negative predictor of grade point average (Moon \& Illingworth, 2005), and a positive predictor of stress (Chu \& Choi, 2005). Although there is a tendency to think of academic procrastination as a U.S. problem, research clearly demonstrates that it is a universal phenomena, which includes Asian countries (Klassen, Krawchuk, \& Rajani, 2010). The exact nature and causative factors responsible for academic

Robert Jay Lowinger, Associate Professor, Psychology, Bluefield State College. Ben C.H. Kuo, Professor, Psychology, University of Windsor. Hyun-A Song, Doctoral candidate, Social Work, University of Pittsburgh. Lakshmi Mahadevan, Assistant Professor \& Extension Specialist, Family Development and Resource Management, Texas A\&M AgriLife Extension. Eunyoung Kim, Associate Professor, Educational Leadership, Management, \& Policy, Seton Hall University. Kelly Yu-Hsin Liao, Visiting Scholar, Psychology, University of Houston. Catherine Y. Chang, Professor \& Program Coordinator, Counselor Education \& Practice, Georgia State University. Kyong-Ah Kwon, Associate Professor, Early Childhood and Elementary Education, Georgia State University. Suejung Han, Assistant Professor, Psychology, Illinois State University. Correspondence concerning this articles should be addressed to Robert Lowinger at rlowinger@bluefieldstate.edu 
procrastination are still a matter of controversy (Steel, 2010). Given that 58\% $(513,910)$ of all international students in the United States are from Asia (Institute of International Education, 2014), it is important to explore the factors associated with academic procrastination in this population.

Researchers have suggested that acculturative stress (Ying \& Han, 2006), lower language proficiency (Yeh \& Inose, 2003), and low academic self-efficacy (Gong \& Fan, 2006) could account for international students' academic problems, including academic procrastination. These difficulties are often more prevalent and severe in Asian students who face greater cultural shock and language barriers as the gap between their native culture and language tends to be greater than for students coming from Europe and other more Westernized parts of the world (Kuo \& Roysircar, 2006). These difficulties could also manifest in procrastination behaviors. Academic procrastination among Chinese international students has been considered as one possible consequence of stress and difficulty resulting from the acculturation and cultural adjustment process (Lowinger, He, Lin, \& Chang, 2014). Increasing research evidence has pointed to coping styles as a critical mitigating factor that affects the quality and experiences of acculturation and cross-cultural adaptation for individuals undergoing cultural transition (Kuo, 2014) and procrastination behavior for students (Alexander \& Onwuegbuzie, 2007). Some researchers have even conceptualized academic procrastination as a manifestation of an avoidant style of coping behavior for the procrastinator (Alexander \& Onwuegbuzie, 2007; Burns, Dittmann, Nguyen, \& Mitchelson, 2000).

\section{Literature Review}

We were unable to identify specific a priori theoretical or conceptual models that could address the broad research questions and encompass the domains of the present study. A number of key predictor variables, which have been implicated to be related to academic procrastination among international students specifically or college students more generally in the extant literature, were identified and examined in the present research. The following section provides a literature review for these variables.

\section{Acculturative Stress}

Asian international students who have lower levels of acculturation tend to have greater levels of stress, distress, and depression (Kuo \& Roysircar, 2006; Wei. et al., 2007). Acculturative stress may be more salient and severe for Asian international students compared to South American or European international students (Fritz, Chin, \& DeMarinis, 2008), or even Asian Americans/Canadians (Kuo \& Roysircar, 2006), because of a greater difference between their home and host cultures (e.g., racial difference, native language is not based on the English alphabet). Lowinger et al. (2014) found that stressors such as culture shock and stress, homesickness, and perceived discrimination were associated with academic procrastination in Chinese international students.

\section{Cross-Cultural Coping}

The manner in which students cope with acculturative stress might be more critical than the degree of acculturative stress in predicting procrastination behaviors. Kuo (2013) defined collective coping as "a constellation of multifaceted stress responses shaped and enhanced by collectivistic norms, values, and tendencies" (p. 4). Collective coping had a negative relationship with adverse/ maladaptive psychological experiences in immigrant Asian adolescents (Wester, Kuo, \& Vogel, 
2006). Collective coping was also found to correlate positively with positive affect among university students (Kuo \& Kwantes, 2014).

Engagement coping, that is, coping using rational problem solving strategies, was found to be effective in reducing depressive symptoms (Noh \& Kaspar, 2003) and psychological distress (Kuo, Arnold, \& Rodriguez-Rubio, 2013; Wester et al., 2006) in Asian and ethnically diverse samples in North America. An avoidance coping style (i.e., not facing a problem or distracting oneself) is related to chronic academic procrastination in a number of other studies (e.g., Burns et al., 2000; Ferrari, Johnson, \& McCown, 1995). The current study employed a culturally derived coping framework and measure based on the Cross-Cultural Coping Scale (CCCS; Kuo, Roysircar, \& Newby-Clark, 2006) to study the effects of coping on academic procrastination in Asian international students.

\section{Language Abilities}

Researchers have reported that lower levels of English proficiency can negatively impact international students' academic performance (e.g., GPA, credits earned) (Poyrazli \& Kavanaugh, 2006; Stoynoff, 1997). Lee, Farruggia, and Brown (2013) found that lower levels of English proficiency were associated with difficulty coping with academic tasks (e.g., ability to manage academic workload, completing assignments on time, making oral presentations). Lowinger et al. (2014) found English language ability predicted procrastination behavior among Chinese female but not among Chinese male international students.

\section{Academic Self-Efficacy}

Academic self-efficacy is a significant predictor of college academic performance beyond the effect of high school grades (Elias \& MacDonald, 2007). A meta-analysis of research in educational settings found academic self-efficacy to explain $11 \%$ of the variance in college students' academic performance (Multon, Brown, \& Lent, 1991).

Klassen, Krawchuk, and Rajani (2007) found a positive correlation between academic selfefficacy and procrastination in a sample of native Canadian university students. In a sample of native Korean college students, Seo (2008) found that academic self-efficacy had a significant negative influence on academic procrastination.

\section{The Present Study}

The main purpose of this study was to assess the impact of acculturative stress and crosscultural coping styles on procrastination behavior in a sample of Asian international students studying in the United States by taking into account the potential effects of their levels of academic self-efficacy and English language proficiency. This study was intended to be an exploratory one, identifying correlates of academic procrastination based on an extensive literature review and empirical exploration. The authors hope that the results of the study will provide a basis for developing future theoretical/conceptual predictor models of academic procrastination for international students.

\section{Research Questions}

Even in native populations, the nature of the predictive variables of academic procrastination are still a matter of considerable controversy (Steel, 2010). As such, researchers have to be particularly cautious with regard to researching and formulating hypotheses on academic 
procrastination involving Asian international students, as there is only one known study which has studied the topic with this population (e.g., Lowinger et al., 2014). For this reason, adhering to the recommendation of Stebbins (2001), we posed research questions: To what degree do each of the following act as predictors of academic procrastination behavior in Asian international students: stress-related variables, coping strategies, academic self-efficacy and English proficiency, and demographic variables.

Despite the fact that we had not been able to identify an a priori conceptual model to conduct hypothesis testing, we explored the joint effects of these critical independent variables on academic procrastination using a multivariate analysis.

\section{Method}

In this section, we describe the methodological procedures involved in the current study of Asian international students. The section addresses: (a) the nature of the sample who participated in the study, (b) the procedures being applied to recruit the current sample, and (c) the measures used in the research.

\section{Participants}

Participants were drawn from a convenience sample of 255 Asian international college students currently enrolled at six universities in the United States: two large public and one large private university in the South, two large public universities in the Midwest, and one large private university in the Northeast. The colleges selected were those with which the study authors had access. The colleges/universities varied from $1 \%$ to $18 \%$ in percentages of international students. A convenience sample is commonly used when it is not feasible to use probabilitybased sampling methods. In convenience sampling, participants are self-selected on their willingness to volunteer to participate in a study (Dunn, 2009). While convenience samples have the potential to yield biased results, they are generally considered acceptable when the participants who volunteer are members of the population under consideration, such as the case where samples of college students are recruited from college classes. In fact, convenience sampling is the most commonly used sampling methodology in studies of college students (McBride, 2010). A convenience sample could be drawn from one or a few colleges. Although a sample of Asian international students drawn from these six colleges might not be representative of Asian international students at these colleges, this sample of students might be more representative of Asian international students, in general, than if the total sample had been drawn from one single college.

The sample was drawn from the general population of students, not from a clinical sample. Of the total sample, $38.8 \%$ were males and $61.2 \%$ were females; $34.0 \%$ were undergraduate students, $66.0 \%$ were graduate students; $30.0 \%$ of the students had been in the United States less than one year, $36.6 \%$ between one and three years, and $33.4 \%$ more than three years. In terms of age, $43.8 \%$ were 18-23 years old, $26.1 \%$ were $24-29$ years old, and $30.1 \%$ were 30 and over. The largest group, $43.2 \%$, reported their majors in the fields of business, education, engineering, journalism, or social work; $24.3 \%$ reported majors in the sciences; $13.5 \%$ in the social sciences; $6.2 \%$ in medicine, nursing, or the health professions; $5.4 \%$ in the fine or performing arts; $1.5 \%$ in the humanities; and the remainder in other unspecified majors. By country of origin, 39.8\% reported their home country as China, $19.3 \%$ reported their home country as Korea, 16.9\%, India, and the rest were divided among a number of other Asian countries. The corresponding national percentages of international students studying in the United States are 31\% from China, $7.7 \%$ from Korea, and 11.6\% from India (Institute of International Education, 2014). 


\section{Procedures}

The students were recruited by letters and emails sent directly to them or through Asian student organizations in the participating colleges. Then they were directed to an online website from which they completed the survey anonymously. The online survey took about 20 minutes to complete.

\section{Measures}

Acculturative Stress. We measured acculturative stress using the Acculturative Stress Scale for International Students (ASSIS; Sandhu \& Asrabadi, 1994). We employed four subscales from the ASSIS to reduce the number of items that participants had to answer: perceived discrimination, homesickness, fear, and culture shock and stress. Each item was rated on a 5point Likert scale ranging from 1 (strongly disagree) to 5 (strongly agree). A sample item is "People from some ethnic groups show hatred toward me nonverbally." The alpha reliability statistics for this sample were perceived discrimination, 0.91; homesickness, 0.69; fear, 0.83; and culture shock and stress, 0.52 .

Cross-Cultural Coping. The CCCS (Kuo et al., 2006) is a scenario-based coping measure designed to assess both individualistic and collectivistic coping strategies. The scale is comprised of three subscales: Collective Coping (CC) (e.g., "I take the course of action that is most acceptable to my family"), Engagement Coping (EC) (e.g., "I put extra effort or work extra hard to resolve the problem"), and Avoidance Coping (AC) (e.g., "I try to block out or forget about what's bothering me"). Participants are asked to imagine being in a hypothetical stressful situation (i.e., dealing with academic pressure) and then rate the likelihood of using various methods of coping in dealing with the described situation using a 6-point Likert scale ranging from 0 (very inaccurate) to 6 (very accurate). Responses are summed such that higher scores reflect greater endorsement of a given coping strategy. In the present study, the CCCS scales demonstrated adequate to good internal consistency (CC, $\alpha=0.75$; EC, $\alpha=0.84$; AC, $\alpha=68$ ).

English Language Ability. In order to assess English ability, we used four items measuring students' self-reported abilities to read, write, understand, and speak college-level English as measured on 5-point Likert scales. This is a commonly used measure of English language ability in international students (Duru \& Poyrazli, 2011). The alpha reliability for this sample was 0.93 .

Academic Self-Efficacy. The academic self-efficacy measure included five items from the Motivated Strategies for Learning Questionnaire (the self-efficacy subscale). The self-efficacy subscale (Pintrich, Smith, Garcia, \& McKeachie, 1993) is widely used and designed to assess students' academic self-efficacy across five domains. Items are measured on 7-point Likert scales with descriptors at 1 (Not at all true of me) and 7 (Very true of me); each person's total score was their mean score across the five domains. A sample item is, "I am confident I can understand the most difficult material presented in the readings in my classes." The alpha reliability for this sample was 0.94 .

Procrastination Behaviour. Procrastination behavior was measured by a single item, which asked whether or not the respondent ever procrastinated on any of their academic responsibilities.

Demographic Information. Demographic information collected included age, gender, marital status, undergraduate/graduate status, major field of study, length of time in the United States, and students' country of origin. 


\section{Limitations}

This study has a number of limitations. First, procrastination behavior was only measured by one dichotomous variable of self-reported frequency of behavior. The rationale for only using one self-reported question to measure procrastination is the probable underreporting of academic procrastination in this population. Asking a standard battery of questions about procrastination such as the Procrastination Assessment Scale for Students (PASS: Solomon \& Rothblum, 1984) most likely resulted in severe underreporting in Asian international students in a previous study (Lowinger et al., 2014). By asking only one question as to whether or not the student "ever procrastinated on any" academic task, we hoped that this would encourage and make it easier for students who might have procrastinated to admit this behavior. Although the $33 \%$ finding of procrastination does not appear unreasonable, given the percentages reported in other studies using the PASS measure which ranged from 7\%-46\% depending upon task (Solomon \& Rothblum, 1984), it is recommended that better instruments are developed for use in future studies. Further, this study used a convenience sample of Asian international students at only six universities; more than two-thirds of the students were graduate students and nearly two-thirds were female; almost three quarters came from China, Korea, and India. Also, the study employed a cross-sectional correlational design not allowing for any attributions of causality among variables.

There were moderate correlations among the independent variables (multicollinearity), so that individual variable effects could not be completely isolated, limiting the confidence, which could be placed in the results of the multiple logistic regression analysis. The large positive correlation between collective and avoidance coping is of concern and requires further investigation. However, this finding is not entirely unexpected, as some cross-cultural coping scholars have considered and measured avoidance and detachment coping as part of the collectivistic coping style associated with Asians (Heppner et al., 2006). Moreover, others have contended that avoidance approaches might be tied to Asians' deep-seated collective values and are motivated by Asians' tendency for "interdependence," "preservation of social harmony," and subsequently, for not "rocking the boat" (Kuo et al., 2006). The R-squared value of the model was only 17\%; many other variables, which were not considered in this study, might play important roles in the prediction of academic procrastination in this population. Such variables might include personality factors such as perfectionism, need for achievement, and the Big Five; motivational factors; study skills, time management, and academic planning strategies. Also, the alpha reliability for the culture shock and stress scale was only 0.52 . However, this could be at least in part because the scale only contained three items. The sample needs to be expanded in terms of the size of subgroup populations, for example, with more undergraduate students, more male students, and larger and more representative samples by country of origin, especially for Indian students, in order to be able to make more definitive statements regarding the nature of subgroup differences.

In spite of these limitations, this study points to the need to devote more attention to the role of coping strategies, academic self-efficacy, and English language proficiency on academic procrastination in Asian international students. Other factors, especially including acculturative stress, engagement coping, personality and motivational variables, time management and academic planning and demographic variables such as age, gender, and country of origin, also need to be explored further as potential predictors of academic procrastination in Asian international students.

\section{Analysis}

There were four kinds of analysis conducted for this study. First, descriptive statistics were reported for all variables. Second, t-tests were used to test for differences by gender, country of 
origin (India vs. other Asian countries), and undergraduate/graduate status. Third, simple bivariate correlations were provided among all independent variables and between each independent variable with the dependent variable. The focus of the correlational analysis was to test the effect of each individual predictor variable on the dependent variable of procrastination. Fourth, a multiple logistic regression analysis (MLR) was conducted on the joint effects of the independent variables on predicting academic procrastination. The MLR provides a method of ascertaining the relative importance of the significant variables taking into account the extent to which the variables might work together to improve prediction or, alternatively, might be overlapping and redundant in their ability to predict academic procrastination.

\section{Results}

The overall percentage of students reporting that they procrastinated on an academic task was $32.7 \%$. There were no significant differences in the percentage of procrastination behavior by undergraduate/graduate status, gender, or country of origin. Descriptive statistics for all variables are reported in Table 1. Female students resided in the United States somewhat longer than male students $(t[255]=2.42, p<0.05)$ and reported more homesickness $(t[255]=2.63, p<0.05)$. There were no statistically significant gender differences on any of the other variables. Undergraduate students resided in the United States longer $(t[255]=2.35, p<0.05)$ and also reported less use of EC $(t[255]=-2.09, p<0.05)$ than graduate students. There were no statistically significant differences between undergraduate and graduate students on any of the other variables.

On the variable of country of origin, Indian students $(n=43)$ reported higher English language ability $(\mathrm{t}[257]=5.48, \mathrm{p}<0.05)$; greater academic self-efficacy $(\mathrm{t}[259]=3.03$, $\mathrm{p}<0.05)$; lower perceived discrimination $(\mathrm{t}[259]=-2.62, \mathrm{p}<0.05)$; fear $(\mathrm{t}[259]=-2.25$, $\mathrm{p}<0.05)$; and acculturative stress $(\mathrm{t}[257]=-2.02, \mathrm{p}<0.05)$. These students reported having been in the United States less time $(\mathrm{t}[255]=-4.07, \mathrm{p}<0.05)$ and were more likely to be single $(\mathrm{t}$ $[257]=2.33, \mathrm{p}<0.05)$ than other Asians. There is no clear evidence in the literature to explain such differences. The only article which we were able to find comparing Indian and other Asian students suggested that Indian students might have better English language skills and understanding of Western culture, although they might be more self-critically perfectionistic and depression prone than other Asian students (Rice, Choi, Zhang, Morero, \& Anderson, 2012). Research regarding Indian international students is clearly warranted. To minimize the heterogeneity of the current Asian international student sample, a decision was made by the research team to not include the Indian students in the subsequent correlational and logistic regression analyses. The relative small size of this group also precluded the possibility of conducting separate predictive analyses for this subgroup.

The overall correlational analyses revealed moderate inter-correlations among some of the independent variables. There was a moderate correlation between academic self-efficacy and English language ability and between academic self-efficacy and EC (which were positively related) as well as among the three measures of acculturative stress: perceived discrimination with culture shock/stress and culture shock/stress with homesickness (which were positively related). There was also a moderate positive correlation between CC and AC (see Table 2). The variables with significant correlations with procrastination were perceived discrimination $(\mathrm{r}=0.19, \mathrm{p}<0.05), \mathrm{CC}(\mathrm{r}=-0.17, \mathrm{p}<0.05)$, and academic self-efficacy $(\mathrm{r}=-0.14, \mathrm{p}<0.05)$ (see Table 2). 
Table 1

Descriptive Statistics: Categorical Variables

\begin{tabular}{|c|c|c|c|c|}
\hline \multirow{2}{*}{$\begin{array}{l}\text { Variables } \\
\text { Student is male }\end{array}$} & \multicolumn{4}{|c|}{$\%$ of total sample } \\
\hline & \multicolumn{4}{|c|}{38.8} \\
\hline Student is undergraduate student & \multicolumn{4}{|c|}{34.0} \\
\hline Student is graduate student & \multicolumn{4}{|c|}{60.0} \\
\hline \multicolumn{5}{|l|}{ Marital relationship } \\
\hline Single & \multicolumn{4}{|c|}{87.6} \\
\hline Married & \multicolumn{4}{|c|}{10.4} \\
\hline Others & \multicolumn{4}{|c|}{2.0} \\
\hline \multicolumn{5}{|l|}{ Length of stay in the U.S. } \\
\hline Less than one year & \multicolumn{4}{|c|}{30.0} \\
\hline Between 1 to 3 years & \multicolumn{4}{|c|}{36.6} \\
\hline Over 3 years & \multicolumn{4}{|c|}{33.4} \\
\hline \multicolumn{5}{|l|}{ Age } \\
\hline $18-23$ years old & \multicolumn{4}{|c|}{43.8} \\
\hline 24-29 years old & \multicolumn{4}{|c|}{26.1} \\
\hline 30 and over & \multicolumn{4}{|c|}{30.1} \\
\hline \multicolumn{5}{|l|}{ Nationality } \\
\hline China & \multicolumn{4}{|c|}{39.8} \\
\hline Korea & \multicolumn{4}{|c|}{19.3} \\
\hline India & \multicolumn{4}{|c|}{16.9} \\
\hline Others & \multicolumn{4}{|c|}{24.0} \\
\hline Ever procrastinated & \multicolumn{4}{|c|}{32.7} \\
\hline Total N & \multicolumn{4}{|c|}{255} \\
\hline Descriptive Statistics: Continuous Variables & \multicolumn{4}{|c|}{255} \\
\hline Variables & Mean & S.D. & Min & Max \\
\hline Student age & 25.15 & 5.31 & 17 & 52 \\
\hline Academic self-efficacy ${ }^{a}$ & 5.151 & 1.392 & 1 & 7 \\
\hline \multicolumn{5}{|l|}{ Acculturative stress ${ }^{b}$} \\
\hline Perceived discrimination & 2.708 & .834 & 1 & 5 \\
\hline Homesickness & 3.035 & .788 & 1 & 5 \\
\hline Perceived fear & 2.415 & .855 & 1 & 5 \\
\hline Culture shock \& stress & 2.774 & .793 & 1 & 5 \\
\hline English proficiency & 3.422 & 1.018 & 1 & 5 \\
\hline \multicolumn{5}{|l|}{ Cross-Cultural Coping Scale ${ }^{d}$} \\
\hline Collective coping (CC) & 3.551 & 1.013 & 1 & 6 \\
\hline Avoidance Coping (AC) & 4.520 & .985 & 1 & 6 \\
\hline Engagement coping (EC) & 3.378 & .879 & 1 & 6 \\
\hline
\end{tabular}

Note. S.D. = standard deviation



${ }^{\mathrm{b}}$ Each item is rated on a 5-point Likert scale ranging from 1 (strongly disagree) to 5 (strongly agree).

c English proficiency level is ranged from 1 (poor) to 5 (excellent).

${ }^{d}$ Each of the Cross-Cultural Coping item is rated on a 6-point Likert scale ranging from 0 (very inaccurate) to 6 (very accurate). 


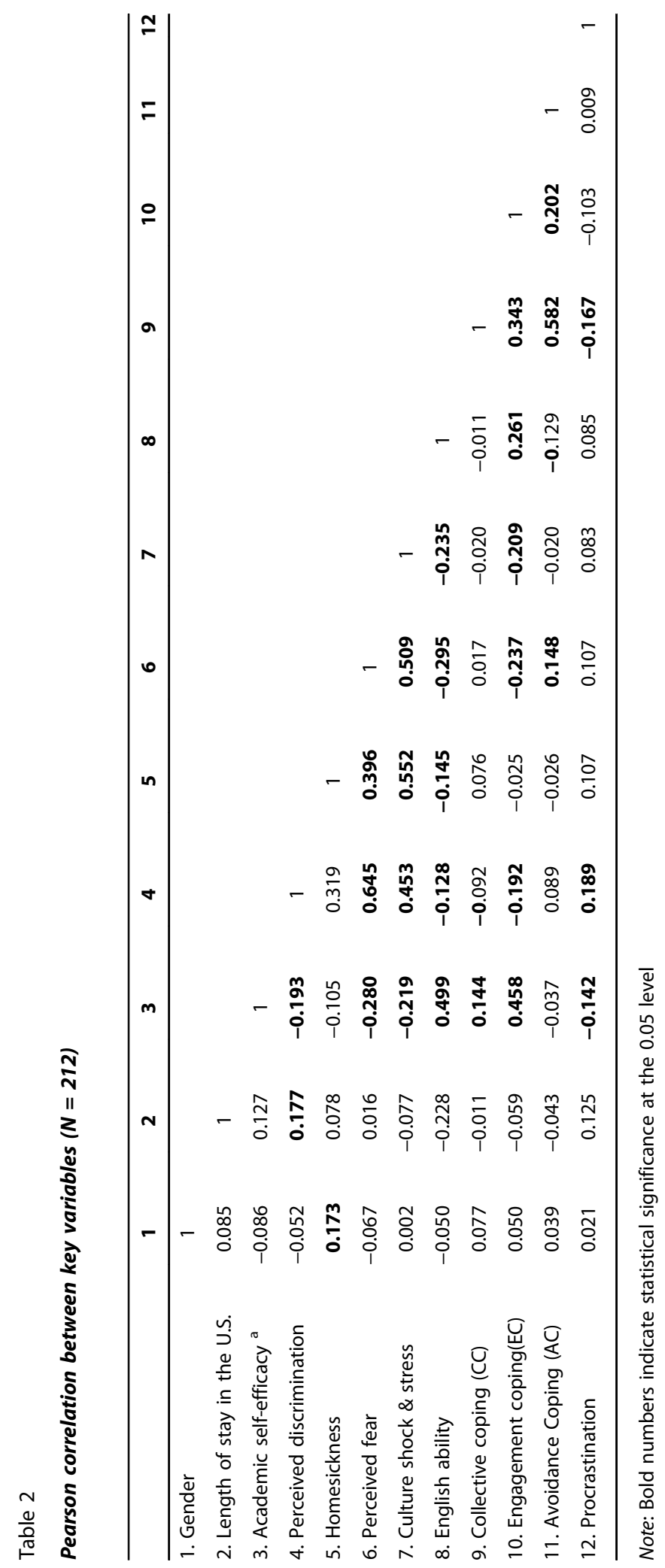


Table 3

Predicting procrastination behavior $(N=212)$

\begin{tabular}{lccc}
\hline & \multicolumn{2}{c}{ Model 1 } \\
\cline { 2 - 4 } Items & \multicolumn{2}{c}{ Procrastination Behavior } & OR \\
\hline & Coefficients & SE & 1.056 \\
Gender & 0.054 & 0.334 & 1.089 \\
Length of stay in the U.S. & 0.085 & 0.095 & 0.729 \\
Academic self-efficacy ${ }^{\mathrm{a}}$ & $-0.316^{*}$ & 0.146 & 1.378 \\
Perceived discrimination & 0.321 & 0.272 & 1.324 \\
Homesickness & 0.281 & 0.260 & 1.667 \\
English proficiency & $0.511^{*}$ & 0.201 & 0.560 \\
Collective coping (CC) & $-0.579^{* *}$ & 0.218 & 0.983 \\
Engagement coping(EC) & -0.017 & 0.200 & 1.641 \\
Avoidance coping (AC) & $0.495^{*}$ & 0.257 & 2.821 \\
Constant & -2.456 & 1.462 & 0.168 \\
$\mathrm{R}^{2} /$ Nagelkerke $\mathrm{R}^{2}$ & & 215 & \\
$\mathrm{~N}$ & & & \\
\hline
\end{tabular}

Note. $\mathrm{SE}=$ robust standard error. $\mathrm{OR}=$ odds ratio.

${ }^{+} p<0.10,{ }^{*} p<0.05 ;{ }^{* *} p<0.01 ;{ }^{* *} p<0.001$.

To examine the relationship between procrastination behavior and the significant predictor variables while controlling for the other significant predictor variables, a MLR was conducted. The results of the MLR (see Table 3) indicated that CC was the largest significant predictor of procrastination when controlling for the other variables with a beta weight of -0.58 (Odds Ratio $(\mathrm{OR})=0.56$ ). This indicates that those who reported higher usage of collective coping are $44 \%$ less likely to engage in procrastination. English proficiency was the second highest predictor of procrastination with a beta weight of $0.51(\mathrm{OR}=1.67)$, indicating that those with higher English proficiency are $67 \%$ more likely to engage in procrastination. The third most significant predictor of academic procrastination was avoidance coping with a beta weight of 0.495 ( $\mathrm{OR}=1.64$ ), indicating that those endorsed an avoidance style of coping were $64 \%$ more likely to procrastinate. The fourth most important predictor was academic self-efficacy, beta weight $=-0.32,(\mathrm{OR}=0.73)$, indicating that those reported higher academic self-efficacy were $27 \%$ less likely to engage in academic procrastination.

\section{Discussion}

The overall percentage of students in this study reporting that they procrastinated on an academic task was 33\%. The percentages of domestic students who procrastinate reported in other research vary considerably depending upon the nature of the sample as well as the nature of the measures used to assess procrastination. It has been suggested that Asian students significantly underreport procrastination behavior, possibly because of feelings of shame associated with this behavior (Lowinger et al., 2014). For Chinese students, Lowinger et al. (2014), using the Procrastination Assessment Scale for Students (PASS), found that procrastination ranged from 
a low of $4 \%$ to a high of $19 \%$, depending upon task versus a corresponding range of $7 \%$ to $46 \%$ for U.S. domestic students (Solomon \& Rothblum, 1984).

While a plethora of variables have been implicated as predictors of academic procrastination, this study shows the importance of collective coping, avoidance coping, English proficiency, and academic self-efficacy as the most critical factors predicting academic procrastination in Asian (non-Indian) students. With regard to stress-related variables, although a number of studies have highlighted the importance of acculturative adjustment factors in the difficulties of Asian international students, this study indicates that these factors are subsumed by other, more important variables. For example, perceived discrimination has been one of the most highlighted variables as predictive of both academic and psychosocial difficulties in Asian international students; yet, perceived discrimination has been shown to result from language difficulties (Wei, Liang, Du, Botello, \& Li, 2015). Those with poorer language skills are more likely to experience discrimination than those with better language skills who can communicate more easily with native American students. Those with better coping skills might experience less acculturation difficulties than those with poorer coping skills. A similar argument could be made with respect to academic self-efficacy: Those with higher academic self-efficacy might experience less acculturative stress; those with lower academic self-efficacy, more acculturative stress. With regard to the importance of cross-cultural coping styles, this study highlights the importance of considering collective coping for its direct impact on procrastination, as CC was the variable with the strongest relationship to procrastination in the predictive model. It is suspected that cultural value-based and in-group referencing characteristics embedded in collective coping might have served to reduce individuals' tendency to engage in "maladaptive" behaviors such as procrastination that could bring shame or dishonor to one's in-group. This interpretation is particularly applicable to Asian students who are imbued with collectivistic norms, values, and tendencies (Kuo, 2013), such that collective coping forms a negative relationship or potentially negates other influences (Wester et al., 2006) such as acculturative stress and other variables explored in this study. The model also found $\mathrm{AC}$ to be a very significant predictor of academic procrastination. This is consistent with studies finding academic procrastination to be a manifestation of an avoidant style of coping behavior for the procrastinator (Ferrari, Johnson, \& McCown, 1995; Ozer \& Ferrari, 2011), although other studies did not find this association (Alexander \& Onwuegbuzie, 2007; Burns et al., 2000). Avoidant procrastination may be perceived as a maladaptive coping mechanism that protects one's self-esteem when faced with adverse tasks: Avoidant procrastination occurs when one distances oneself from a task because the task is viewed as adverse, or the person may be blamed for a lack of progress on a task reflecting poor skill levels (Díaz-Morales, Cohen, \& Ferrari, 2008a).

With regard to language and academic self-efficacy as predictors of academic procrastination in Asian international students, this study found the following: while English language proficiency was hypothesized to relate to procrastination through the influence of academic stress, such that poorer language skills result in more acculturative stress and greater procrastination, the results of this study support a very different hypothesis. Namely, students with greater language skills actually report greater levels of procrastination. This could potentially be explained by the possibility that those international students with greater English language skills might have been more distracted by the mainstream "American" activities, such as spending more time socializing with Americans and other recreational interests and, as a result, delayed attending to their school work and responsibilities. This hypothesis is plausible and consistent with McCown and Johnson's (1991) study of native American students; they found that native American students who were higher in extraversion had greater interference in examination studying due to their participation 
in more pre-planned social activities. Also, academic self-efficacy was statistically significant as a negative predictor of procrastination in the multivariate model. This finding is consistent with Social Learning Theory (Bandura, 1986) and empirical findings in other studies (Lowinger et al., 2014). Lee, Bong, and Kim (2014) found a strong relationship between self-efficacy and maladaptive academic behavior including procrastination in Korean high school students; they accounted for this by noting that when self-efficacy was low on important academic tasks, there was a threat to self-worth which resulted in procrastination behavior.

Demographic factors such as gender, marital status, length of time in the United States, and undergraduate/graduate status were not found to be important predictors of procrastination. This could indicate that demographic variables, along with acculturative variables and EC, were redundant with, incorporated by, and superseded by $\mathrm{CC}, \mathrm{AC}$, academic self-efficacy, and English language proficiency as determinants of procrastination behavior in this population.

\section{Implications}

One of the most significant barriers to the development of effective interventions for academic procrastination is the lack of understanding of the constructs responsible for causing and maintaining the behavior (Glick \& Orsillo, 2015). While we are not in a position to delineate effective interventions for academic procrastination behavior in Asian international students, we believe that this research can be used to provide some general guidance. To help international students of Asian backgrounds to avoid procrastination behavior and improve academic functioning, we would suggest student affairs professionals establish programs to encourage the use of effective coping strategies, especially collective coping, discourage and provide alternatives to the use of avoidance coping, improve academic self-efficacy, and directly address procrastination behavior itself

Our results suggest that it could be useful to help Asian international students use collective coping strategies (such as thinking about or consulting with one's family or friends when faced with a problem) while also encouraging an appreciation of their own cultural heritage. The latter would be compatible with an effort to also help them acculturate to U.S. social norms; working on both could actually facilitate the development of an integrated cultural identity and enhance psychological adjustment (Berry, 2005). Yeh and Inose (2002) suggested that professionals working with Asian students improve collectivistic coping strategies by engaging social support networks and collaborating with community members such as parents, faculty, and counselors. One concrete intervention program or strategy is for college student affairs personnel to establish a coethnic mentoring program employing positive mentoring from other more experienced and welladjusted Asian students who share similar national, language, and cultural backgrounds. Having a constructive role model from one's own in-group can serve to augment Asian students' sense of ethnic identity and also can enhance their collective value and identity as they navigate through academic and adjustment challenges in the United States. Student affairs administrators could set up psycho-educational workshops or one credit hour classes to help educate Asian international students about coping styles to deal with acculturative stress, improve academic self-efficacy, encourage socialization with Americans, and minimize academic procrastination.

Student affairs professionals could organize social events inside and outside the college setting for international students to interact with each other and with native students helping to promote acculturation and reduce feelings of perceived discrimination. Ying (2003) found that social relationships with Americans and a strong support network were particularly important for the academic achievement of Taiwanese students studying in the United States. Students experiencing significant language and communication difficulties should also be referred to appropriate college 
resources to improve English language skills. This study suggests that increased language skills and socialization activities might also promote academic procrastination. Programs should include components to address the potential unintended consequences of international students becoming more acculturated (e.g., becoming more proficient in English) in the U.S. life style, including increased, unproductive social activities and distractions. Clinical service providers are probably the most suitable student affairs professionals to develop or provide intervention services for students with more severe procrastination problems. Most clinical interventions for academic procrastination are based on behavioral or motivational approaches (Schouwenburg, Lay, Pychyl, \& Ferrari, 2004).

Wherever feasible, student support services to this population should be advertised and promoted as "educational" rather than "counseling" services because of the well-documented reluctance of Asian international students to use counseling services/resources (Yakunina \& Weigold, 2011). Student affairs professionals working with international students should also be sensitive to Asian students' reluctance to disclose personal information such as study behavior patterns and be advised to consider college grades and work performance to signal the possibility of academic procrastination issues

This study also raises additional issues, which might be potentially important to explore in future research. One issue would be the potential differences in Indian students as compared with other Asian students in terms of acculturative stress and coping styles. Our limited sample of Indian students had higher English language ability and greater academic self-efficacy; testing this result in larger samples and exploring if these factors help account for Indian students employing strategies other than collective coping (e.g., engagement coping) to prevent procrastination is important. A second issue to determine is to what extent students were able to successfully cope with academic procrastination or were overwhelmed by it, perhaps to the point of having to prematurely return to their home countries. A third issue would be to ascertain whether the students ultimately completed the tasks which they reported that they procrastinated on. If students do not ultimately complete these tasks, it provides additional support for procrastination as a detriment to academic performance. A fourth issue would be to further explore the relationship among the independent variables used in this study which were not significant (e.g., length of time in the United States, homesickness, culture shock, and EC), especially the extent to which these variables relate with a collective coping style, avoidance coping style, academic self-efficacy, and English proficiency relative to the prediction of academic procrastination in Asian international students. Lastly, larger and more statistically representative samples of Asian international students are needed in this area of research. While convenience sampling is commonly employed in the study of college populations, sampling would be greatly improved if both the procedure for selecting colleges/universities as well as the students within them were based on probabilistic sampling methodologies.

\section{References}

Alexander, E. S., \& Onwuegbuzie, A. J. (2007). Academic procrastination and the role of hope as a coping strategy. Personality and Individual Differences, 42(7), 1301-1310. doi:10.1016/j.paid.2006.10.008

Bandura, A. (1986). Social foundations of thought and action: A social cognitive theory. Englewood Cliffs, NJ: Prentice-Hall.

Berry, J. (2005). Acculturation: Living successfully in two cultures. International Journal of Intercultural Relations, 29(6), 697712. doi:10.1016/j.ijintrel.2005.07.013

Burns, L. R., Dittmann, K., Nguyen, N. L., \& Mitchelson, J. K. (2000). Academic procrastination, perfectionism, and control: Associations with vigilant and avoidant coping. Journal of Social Behavior and Personality, 15(5), 35-46.

Chu, A. H. C., \& Choi, J. N. (2005). Rethinking procrastination: positive effects of "active" procrastination behavior on attitudes and performance. Journal of Social Psychology, 145(3), 245-264. 
Díaz-Morales, J., Cohen, J., \& Ferrari, J. (2008a). An integrated view of personality styles related to avoidant procrastination. Personality \& Individual Differences, 45(6), 554-558. doi:10.1016/j.paid.2008.06.018

Dunn, D. S. (2009). Research methods for social psychology. West Sussex, UK: Wiley-Blackwell.

Duru, E., \& Poyrazli, S. (2011). The role of demographics, English language competency, perceived discrimination and social connectedness in predicting level of adjustment difficulties among Turkish international students in the U.S. The International Journal of Psychology, 46(6), 446-454. doi:10.1080/00207594.2011.585158

Elias, S. M., \& MacDonald, S. (2007). Using past performance, proxy efficacy, and academic self-efficacy to predict college performance. Journal of Applied Social Psychology, 37(11), 2518-2531. doi:10.1111/jasp.2007.37.issue-11

Ferrari, J. R., Johnson, J. L., \& McCown, W. G. (1995). Procrastination and task avoidance. New York, NY: Plenum Press.

Fritz, M. V., Chin, D., \& DeMarinis, V. (2008). Stressors, anxiety, acculturation and adjustment among international and North American students. International Journal of Intercultural Relations, 32(3), 244-259. doi:10.1016/j.ijintrel.2008.01.001

Glick, D. M., \& Orsillo, S. M. (2015). An investigation of the efficacy of acceptance-based behavioral therapy for academic procrastination. Journal of Experimental Psychology: General, 144(2), 400-409. doi:10.1037/xge0000050

Gong, Y., \& Fan, J. (2006). Longitudinal examination of the role of goal orientation in cross-cultural adjustment. Journal of Applied Psychology, 91(1), 176-184. doi:10.1037/0021-9010.91.1.176

Heppner, P. P., Heppner, M. J., Lee, D. G., Wang, Y. W., Park, H. J., \& Wang, L. F. (2006). Development and validation of a collectivist coping styles inventory. Journal of Counseling Psychology, 53(1), 107-125. doi:10.1037/0022-0167.53.1.107

Institute of International Education. (2014). Open doors: International students in the U.S. Retrieved from file:// http://www.iie. org/research-and-publications/open-doors/data

Klassen, R. M., Krawchuk, L. L., \& Rajani, S. (2007). Academic procrastination of undergraduates: Low self-efficacy to selfregulate predicts higher levels of procrastination. Contemporary Educational Psychology, 33(4), 915-931. doi:10.1016/j. cedpsych.2007.07.001

Klassen, R. M., Ang, R. P., Chong, W. H., Krawchuk, L. L., Huan, V .S., Wong, I. Y. F., \& Yeo, L. S. (2010). Academic procrastination in two settings: motivation correlates, behavioral patterns, and negative impact of procrastination in Canada and Singapore. Applied Psychology: An International Review, 59(3), 361-379.

Kuo, B. C. H. (2013). Collectivism and coping: Current theories, evidence, and measurements of collective coping. International Journal of Psychology, 48(3), 374-388. doi:10.1080/00207594.2011.640681

Kuo, B. C. H. (2014). Coping, acculturation, and psychological adaptation among migrants: A theoretical and empirical review and synthesis of the literature. Health Psychology and Behavioral Medicine: An Open Access Journal, 2(1), 16-33. doi:10.1080/21642850.2013.843459

Kuo, B. C. H., Arnold, R., \& Rodriguez-Rubio, B. (2013). Mediating effects of coping in the link between spirituality and psychological distress in a culturally diverse undergraduate sample. Mental Health, Religion, and Culture, 17(2), $173-184$. doi:10.1080/13674676.2013.780015

Kuo, B. C. H., \& Kwantes, C. T. (2014). Testing predictive models of positive and negative affect with psychosocial, acculturation, and coping variables in a multiethnic undergraduate sample. SpringerPlus, 3, 119. doi:10.1186/21931801-3-119

Kuo, B. C. H., \& Roysircar, G. (2006). An exploratory study of cross-cultural adaptation of adolescent Taiwanese unaccompanied sojourners in Canada. International Journal of Intercultural Relations, 30(2), 159-183. doi:10.1016/j. ijintrel.2005.07.007

Kuo, B. C. H., Roysircar, G., \& Newby-Clark, I. R. (2006). Development of the cross-cultural coping scale: Collective, avoidance, and engagement strategies. Measurement and Evaluation in Counselling and Development, 39(3), 161-181.

Lee, B., Farruggia, S. P., \& Brown, G. T. L. (2013). Academic difficulties encountered by East Asian international university students in New Zealand. Higher Education Research \& Development, 32(6), 915-931. doi:10.1080/ 07294360.2013 .806444

Lee, J., Bong, M., \& Kim, S. (2014). Interaction between task values and self-efficacy on maladaptive achievement strategy use. Educational Psychology, 34(5), 538-560. doi:10.1080/01443410.2014.895296

Lowinger, R. J., He, Z., Lin, M., \& Chang, M. (2014). The impact of academic self-efficacy, acculturation difficulties, and language abilities on procrastination behavior in Chinese international students. College Student Journal, 48(1), 141-152.

McBride, D. M. (2010). The process of research in psychology. Thousand Oaks, CA: SAGE.

McCown, W., \& Johnson, J. (1991). Personality and chronic procrastination by university students during an academic exam period. Personality and Individual Differences, 12, 413-415.

Moon, S. M., \& Illingworth, A. J. (2005). Exploring the dynamic nature of procrastination: A latent growth curve analysis of academic procrastination. Personality and Individual Differences, 38(2), 297-309. doi:10.1016/j.paid.2004.04.009

Multon, K. D., Brown, S. D., \& Lent, R. W. (1991). Relation of self-efficacy beliefs to academic outcomes: A meta-analytic investigation. Journal of Counseling Psychology, 38(1), 30-38. doi:10.1037/0022-0167.38.1.30

Noh, S., \& Kaspar, V. (2003). Perceived discrimination and depression: Moderating effects of coping, acculturation, and ethnic support. American Journal of Public Health, 93(2), 232-238. doi:10.2105/AJPH.93.2.232

Özer, B. U., Demir, A., \& Ferrari, J. R. (2009). Exploring academic procrastination among Turkish students: Possible gender differences in prevalence and reasons. The Journal of Social Psychology, 149(2), 241-257. doi:10.3200/SOCP.149.2.241257

Pintrich, P. R., Smith, D. A. F., Garcia, T., \& McKeachie, W. J. (1993). Reliability and predictive validity of the motivated strategies for learning questionnaire (MSLQ). Educational and Psychological Measurement, 53(3), 801-813. doi:10.1177/ 0013164493053003024

Poyrazli, S., \& Kavanaugh, P. (2006). Marital status, ethnicity, academic achievement, and adjustment strains: The case of graduate international students. College Student Journal, 40(4), 767-780. 
Rice, K. G., Choi, C. C., Zhang, Y., Morero, Y. I., \& Anderson, D. (2012). Self-critical perfectionism, acculturative stress, and depression among international students. Counseling Psychologist, 40(4), 575-600. doi:10.1177/0011000011427061

Sandhu, D. S., \& Asrabadi, B. R. (1994). Development of an acculturative stress scale for international students: Preliminary findings. Psychological Reports, 75(1), 435-448. doi:10.2466/pr0.1994.75.1.435

Schouwenburg, H. C., Lay, C. H., Pychyl, T. A., \& Ferrari, J. R. (Eds.). (2004). Counseling the procrastinator in academic settings. Washington, DC: American Psychological Association.

Seo, E. H. (2008). Self-efficacy as a mediator in the relationship between self-oriented perfectionism and academic procrastination. Social Behavior and Personality, 36(6), 753-764. doi:10.2224/sbp.2008.36.6.753

Solomon, L. J., \& Rothblum, E. D. (1984). Academic procrastination: Frequency and cognitive-behavioral correlates. Journal of Counseling Psychology, 31(4), 503-509. doi:10.1037/0022-0167.31.4.503

Stebbins, R. A. (2001). Exploratory research in the social sciences. Thousand Oaks, CA: SAGE.

Steel, P. (2010). Arousal, avoidant and decisional procrastinators: Do they exist? Personality and Individual Differences, 48(8), 926-934. doi:10.1016/j.paid.2010.02.025

Stoynoff, S. (1997). Factors associated with international students' academic achievement. Journal of Instructional Psychology, 24(1), 56-68.

Wei, M., Liang, Y.-S., Du, Y., Botello, R., \& Li, C.-I. (2015, April 6). Moderating effects of perceived language discrimination on mental health outcomes among Chinese international students. Asian American Journal of Psychology, Advance online publication. 6, 213-222. doi:10.1037/aap0000021

Wei., M., Mallen, M., Heppner, P., Ku, T.-Y., Liao, Y.-H., \& Wu, T.-F. (2007). Acculturative stress, perfectionism, years in the United States, and depression among Chinese international students. Journal of Counseling Psychology, 54(4), 385-394. doi:10.1037/0022-0167.54.4.385

Wester, S. R., Kuo, B. C. H., \& Vogel, D. L. (2006). Multicultural coping: Chinese-Canadian adolescents, male gender role conflict, and psychological distress. Psychology of Men and Masculinity, 7(2), 87-104. doi:10.1037/1524-9220.7.2.83

Yakunina, E. S., \& Weigold, I. K. (2011). Asian international students' intentions to seek counseling: Integrating cognitive and cultural predictors. Asian American Journal of Psychology, 2(3), 219-224. doi:10.1037/a0024821

Yeh, C. J., \& Inose, M. (2002). Difficulties and coping strategies of Chinese, Japanese, and Korean immigrant students. Adolescence, 37(145), 69-82.

Yeh, C. J., \& Inose, M. (2003). International students' reported English fluency, social support satisfaction, and social connectedness as predictors of acculturative stress. Counseling Psychology Quarterly, 16(1), 15-28. doi:10.1080/ 0951507031000114058

Ying, Y. W. (2003). Academic achievement and quality of overseas study among Taiwanese students in the United States. College Student Journal, 37(3), 470-480.

Ying, Y. W., \& Han, M. (2006). The contribution of personality, acculturative stressors, and social affiliation to adjustment: A longitudinal study of Taiwanese students in the United States. International Journal of Intercultural Relations, 30(5), 623635. doi:10.1016/j.ijintrel.2006.02.001 